\title{
Immobilisation causes longlasting matrix changes both in the immobilised and contralateral joint cartilage
}

\author{
Matti O Jortikka, Ritva I Inkinen, Markku I Tammi, Jyrki J Parkkinen, Jussi Haapala, \\ Ilkka Kiviranta, Heikki J Helminen, Mikko J Lammi
}

Departments of Anatomy, University of Kuopio

O Jortikka

R I Inkinen

M I Tammi

H J Helminen

M J Lammi

Pathology, University of Kuopio

J J Parkkinen

and Surgery

J Haapala

Kuopio University

Hospital, FIN-70211

Kuopio, Finland

Department of

Surgery, Jyväskylä

Central Hospital,

Jyväskylä, Finland

I Kiviranta

Correspondence to:

Dr M Lammi, Department

of Anatomy, University of

Kuopio, PO Box 1627,

FIN-70211 Kuopio, Finland.

Accepted for publication

21 January 1997

\begin{abstract}
Objective-The capacity of articular cartilage matrix to recover during 50 weeks of remobilisation after an atrophy caused by 11 weeks of immobilisation of the knee (stifle) joint in $90^{\circ}$ flexion starting at the age of 29 weeks, was studied in young beagle dogs.

Methods-Proteoglycan concentration (uronic acid) and synthesis $\left(\left[{ }^{35} \mathrm{~S}\right]\right.$ sulphate incorporation) were determined in six and three knee joint surface locations, respectively. Proteoglycans extracted from the cartilages were characterised by chemical determinations, gel filtration, and western blotting for chondroitin sulphate epitope 3 B3.
\end{abstract}

Results-The proteoglycan concentrations that were reduced in all sample sites immediately after the immobilisation, remained $14-28 \%$ lower than controls after 50 weeks of remobilisation in the patella, the summit of medial femoral condyle, and the superior femoropatellar surface. In the contralateral joint, there was a $49 \%$ increase of proteoglycans in the inferior femoropatellar surface after remobilisation, while a $34 \%$ decrease was simultaneously noticed on the summit of the medial femoral condyle. Total proteoglycan synthesis was not significantly changed after immobilisation or 50 weeks' remobilisation in the treated or contralateral joint, compared with age matched controls. The chondroitin 6- to 4- sulphate ratio was reduced by immobilisation both in the radioactively labelled and the total tissue proteoglycans. In the remobilised joint, this ratio was restored in femur, while in tibia it remained at a level lower than controls. Neither immobilisation nor remobilisation induced epitopes recognised by the monoclonal antibody $3 B 3$ on native (undigested) proteoglycans.

Conclusion-These results show that the depletion of proteoglycans observed after 11 weeks of immobilisation was not completely restored in certain surface sites after 50 weeks of remobilisation. The significant changes that developed in the contralateral joint during the remobilisation period give further support to the idea that a permanent alteration of matrix metabolism results even from a tempo- rary modification of loading pattern in immature joints.

(Ann Rheum Dis 1997;56:255-261)

Diarthrodial joints form a most exceptional system enabling both the movement and weight bearing of the limbs. The articular cartilage, covering the surfaces of bone ends, is composed of chondrocytes embedded in a matrix consisting of highly anionic, hydrated proteoglycans, and a network of collagen fibrils. ${ }^{12}$ The composition and structure of the articular cartilage give this tissue its unique biophysical properties that are largely determined by the extent of loading of the joints. $^{3}$

Immobilisation and reduced weight bearing have been shown to cause remarkable changes in the properties of articular cartilage. ${ }^{4-6}$ Cartilage atrophy caused by the lack of weight bearing in a freely moving knee joint of an amputated leg has been reported. ${ }^{7}$ Increase in matrix protease levels and depression of tissue inhibitor of metalloproteases have been associated with the disuse atrophy. ${ }^{8}$ Degenerative cartilage changes were noticed in a light microscopic stereological study on rabbit knees immobilised in extension. ${ }^{9}$ In the dog, immobilisation seemed to protect cartilage against osteoarthritis induced by transection of the anterior cruciate ligament ${ }^{10}$ or chemical injury. ${ }^{11}$

On the other hand, increased weight bearing, such as occurs in the contralateral to the immobilised joint, also promotes matrix changes in the cartilage. Glycosaminoglycan content is often increased after increased weight bearing in the canine and ovine joints, ${ }^{52-15}$ while in rabbits it was unchanged or decreased. ${ }^{16-18}$ In dogs and rabbits, comparatively more keratan sulphate was found in the contralateral cartilage, ${ }^{17}{ }^{19}$ whereas in the sheep chondroitin sulphate content was increased. ${ }^{13}$

Earlier studies on the properties of articular cartilage after remobilisation have given somewhat variable results. ${ }^{515^{120-24}}$ In a well characterised dog model we found earlier that a remobilisation period of 15 weeks did not completely restore the glycosaminoglycan content ${ }^{1415}$ or the biomechanical properties ${ }^{23}$ of the articular cartilage. The aim of this study was to examine whether a longer remobilisation (50 weeks) would return these values to the level of the age matched controls, or whether a 
permanent change in cartilage matrix occurs after a temporary change of joint loading in young animals.

\section{Methods}

ANIMALS

Seventeen pairs of female beagle dogs of pure breed were provided by the Marshall Farms (North Rose, NY, USA). Each pair (experimental and control animal) was chosen from the same litter. During the experiment, the dogs were housed in standard cages with a bottom area of $0.9 \times 1.2 \mathrm{~m}$ according to the $\mathrm{NIH}$ recommendations for care and use of laboratory animals. ${ }^{25}$

IMMOBILISATION

The right knee (stifle) joint of one animal from each pair (17 dogs) was immobilised in $90^{\circ}$ flexion with a fibreglass cast (Dynacast Pro, Smith \& Nephew Medical Limited, Hull, UK) at the age of 29 weeks, for the duration of next 11 weeks. The cast was tied to the trunk, which prevented the weight bearing and restricted the movement of the joint. ${ }^{14}$ It also caused a $30-50 \%$ increase in the weight bearing of the untied hind limb ( $T$ Lyyra, unpublished data). At the age of 40 weeks, eight of the experimental animals and their littermate control animals $(n=8)$ were killed by an overdose of barbiturate, and cartilage samples were prepared for metabolic labelling.

\section{REMOBILISATION}

The casts of the rest of the immobilised dogs $(n=9)$ were removed at the age of 40 weeks and the dogs were allowed to ambulate freely in their cages for 50 weeks (remobilisation group). These dogs and their littermate controls $(n=9)$ were killed as described above and cartilage samples were metabolically labelled and biochemically analysed. The design of this experiment was approved by the ethical committee for animal experiments at the University of Kuopio.

\section{SAMPLE PREPARATION AND METABOLIC}

LABELLING

Knee joints from the right hind limb of control animals, and from both hind limbs of the immobilised and remobilised groups, were dissected free of soft tissues. Two full depth cartilage slices (width $1 \mathrm{~mm}$ ), including the underlying bone, were prepared from six different sample sites: inferior femoropatellar area, FPI; superior femoropatellar area, FPS; anterior medial femoral condyle, FMA; intermediate medial femoral condyle, FMI; medial tibial condyle, TM; and patella, PAT (fig 1). A part of the slices was labelled with $\left[{ }^{35} \mathrm{~S}\right]$ sulphate. ${ }^{26}$ Articular cartilage was separated from the bone and the wet weight of the sample was recorded. Total sulphate incorporation of the tissue was quantified using PD-10 columns (Pharmacia, Uppsala, Sweden) to separate incorporated $\left[{ }^{35} \mathrm{~S}\right]$ sulphate from the free precursor after proteinase $\mathrm{K}$ digestion of the cartilage. ${ }^{26}$ The molar concentrations of chondroitin 6- and 4-sulphate isomers were determined by ultraviolet absorbance at 232 $\mathrm{nm}$ of the chondroitinase AC generated unsaturated disaccharides from metabolically labelled cartilage samples predigested with proteinase $\mathrm{K}$. The separation was achieved by high performance liquid chromatography on a Carbopak PA1 column (Dionex, Sunnyvale, CA). ${ }^{27}$ Radioactivity in the fractions was quantified by liquid scintillation counting.

\section{EXTRACTION OF PROTEOGLYCANS}

For biochemical analyses of proteoglycans, articular cartilage was cut into $20 \mu \mathrm{m}$ thick sections and freeze dried. The dry weights were recorded, and proteoglycans were extracted under dissociative conditions in the presence of proteinase inhibitors for 24 hours at $4{ }^{\circ} \mathrm{C} .{ }^{26}$ The extraction residue was digested with proteinase $\mathrm{K}$, and proteoglycans were precipitated with three volumes of ethanol at $4{ }^{\circ} \mathrm{C} .{ }^{26}$ Uronic acid contents both in the extract and the extraction residue were determined ${ }^{28}$ to obtain the total amount and extractability of cartilage proteoglycans.

WESTERN BLOTTING FOR MONOCLONAL

ANTIBODY 3B3 EPITOPES

Proteoglycan subpopulations present in the extracts were examined by SDS-agarose gel electrophoresis. After desalting of the extracts the ethanol precipitated proteoglycans were electrophoresed in submerged $0.75 \%(\mathrm{w} / \mathrm{v})$ agarose slab gels, ${ }^{29}$ and transferred onto a PVDF membrane using a semi-dry electroblotter. The monoclonal antibody $3 \mathrm{~B} 3^{30}$ was used to detect chondroitin sulphate epitopes, before and after the membranes were treated with chondroitinase $\mathrm{ABC}(0.01 \mathrm{U} / \mathrm{ml}$ in $0.2 \mathrm{M}$ TRIS, $60 \mathrm{mM}$ sodium acetate, $\mathrm{pH} 8.0$ ) at $37^{\circ} \mathrm{C}$ for one hour. After incubation of peroxidase conjugated antimouse Igs, the epitopes were visualised by the Renessaince chemiluminescence system (DuPont, Boston, MA, USA).

SEPHACRYL S-500 GEL FILTRATION

Parts of the individual extracts in each experimental group were combined, and aliquots of the pools $(100 \mu \mathrm{g}$ of uronic acid) were transferred into the elution buffer (4 M guanidinium hydrochloride, $0.5 \%$ CHAPS, 10 $\mathrm{mM} \mathrm{Na}_{2} \mathrm{SO}_{4}$ and protease inhibitors in $0.05 \mathrm{M}$ Na-acetate, $\mathrm{pH}$ 6.0) using PD-10 columns. Triplicate samples were chromatographed on an $1 \mathrm{~cm} \times 30 \mathrm{~cm}$ column of Sephacryl S-500 (Pharmacia) at a $10 \mathrm{ml} / \mathrm{h}$ flow rate. Aliquots of the fractions $(500 \mu \mathrm{l})$ were analysed for proteoglycans by safranin $\mathrm{O}$ precipitation ${ }^{31}$ and for radioactivity by liquid scintillation counting.

RELATIVE GLYCOSAMINOGLYCAN CHAIN LENGTHS The relative chain lengths of glycosaminoglycans of the extracted proteoglycans were compared by Sephacryl S-300 (Pharmacia) gel chromatography. The extracts were desalted, lyophilised, and reduced by alkaline borohydride as described previously. ${ }^{26}$ A Sephacryl S-300 column $(1 \times 30 \mathrm{~cm})$ was eluted with 0.1 $\mathrm{M}$ Na-phosphate, $\mathrm{pH} 7.0,0.5 \%$ CHAPS, 0.15 $\mathrm{M} \mathrm{NaCl}$, and $10 \mathrm{mM} \mathrm{Na}_{2} \mathrm{SO}_{4}$ at flow rate of 10 
$\mathrm{ml} / \mathrm{h}$. The fractions $(500 \mu \mathrm{l})$ were then analysed for glycosaminoglycans by cuprolinic blue precipitation. $^{32}$

STATISTICAL ANALYSES

To calculate the significance of differences observed between the different groups, Wilcoxon's matched pairs signed ranks test was used.

\section{Results}

MACROSCOPIC FINDINGS

The physical activity between the immobilised and control groups appeared similar after two to three days of application of the cast; the dogs moved about easily with three feet. An equal time lapsed before normal looking use of the leg after removal of the cast. The body weights of the age matched control and experimental groups were equal. The surfaces of all knee joints were carefully examined to detect any signs of damage possibly caused by the treatments. Macroscopically, the articular surfaces were shiny and smooth, and neither injury nor fibrillation could be observed in any of the inspected joints.

WATER AND URONIC ACID CONTENTS

Uronic acid concentration was significantly reduced after 11 weeks of immobilisation in the superior femoropatellar area (FPS), anterior medial femoral condyle (FMA) and medial condyle of tibia (TM), the inferior femoropatellar area (FPI), whereas a non-significant decline was noticed in the patella (PAT) and in the intermediate medial femoral condyle (FMI) (fig 1). Water content increased significantly in the superior femoropatellar area (FPS), anterior medial femoral condyle (FMA), and medial condyle of tibia (TM) (data not shown).

The concentration of uronic acid in the remobilised limb remained significantly lower $(28 \%)$ than that in the age matched controls in the superior section of the patellar surface of femur (FPS), while it was only slightly lower or close to the control level in all other sample sites (fig 1). Interestingly, the contralateral limb of the remobilised animal showed a statistically significant increase of uronic acid in the inferior section of the patellar surface of femur (FPI), while a significant decrease was noticed in the intermediate section of the medial condyle of the femur (FMI).

In the remobilised joint, no significant differences were seen in water content compared with the age matched control animals. However, it was significantly lower in the anterior medial femoral condyle (FMA) cartilage of the joint contralateral to the remobilised one. A comparison between the remobilised and its contralateral joint showed significantly higher water content in the remobilised FPI and FMA.

Extractability of proteoglycans varied between $73 \%$ and $98 \%$ of the total uronic acid,
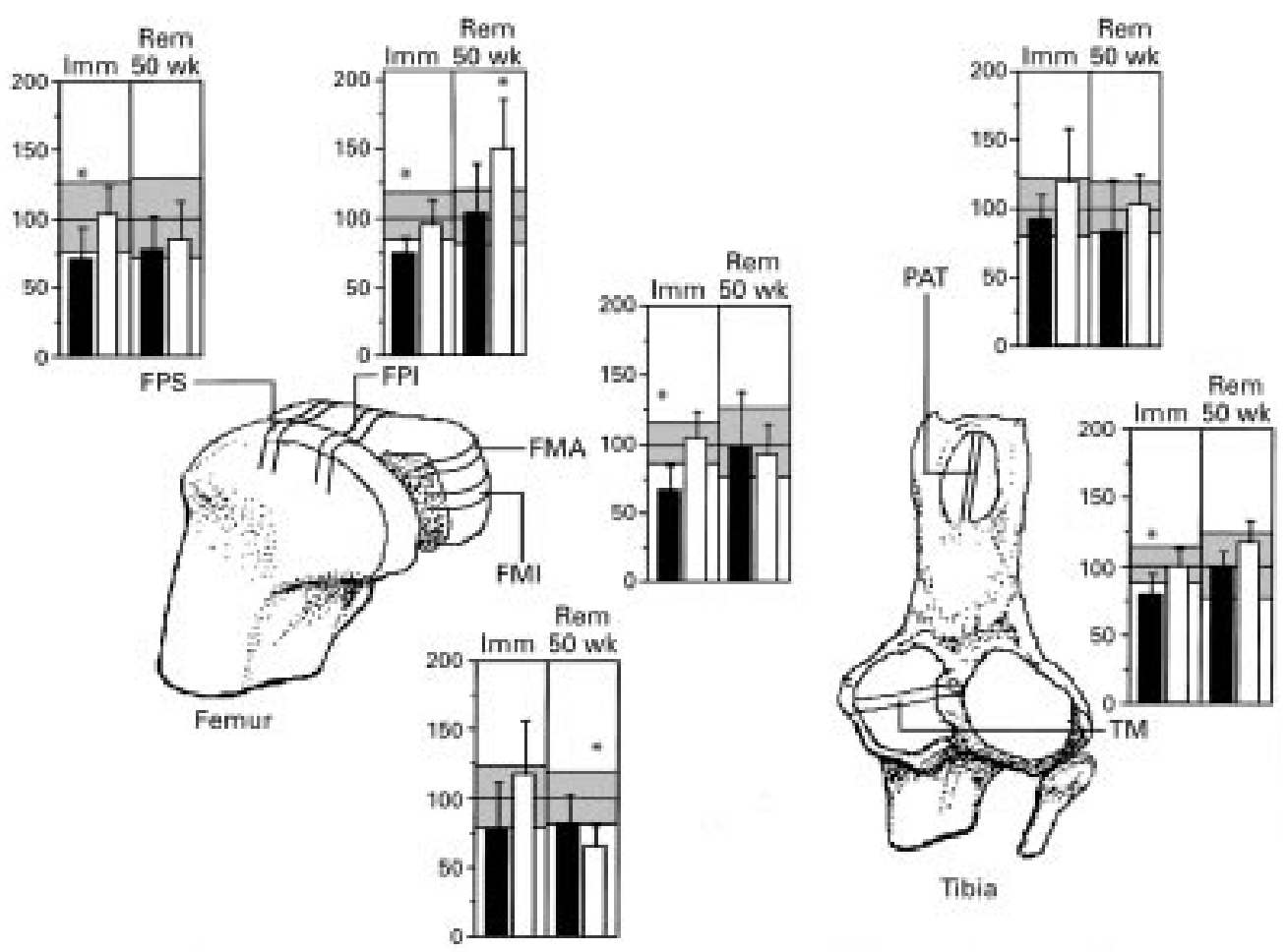

Figure 1 Concentration of extractable uronic acid in the articular cartilage of canine knee joints after 11 weeks of immobilisation (Imm), and after 50 weeks' remobilisation (Rem) of the limb that had been cast. The concentration of uronic acid was measured as nmol per $\mathrm{mg}$ wet weight, and the results were normalised to the level of littermate control animals (100\% level shown in the figure). The shaded range in the background of each histogram indicates 1 SD from the mean of controls. Superior femoropatellar area, FPS; inferior femoropatellar area, FPI; anterior medial femoral condyle, FMA; intermediate section of the medial femoral condyle, FMI; patella, PAT; medial tibial condyle, TM; filled bars, immobilised or remobilised joint; open bars, contralateral joint. Asterisk shows significant changes $(p \leq 0.05)$ compared with age matched control group. 
Table 1 Sulphate incorporation rates (pmol/mg wet weight) and ratios of chondroitin 6-sulphate to chondroitin 4-sulphate in the canine articular cartilage (mean (SD)) after 11 weeks' immobilisation and 50 weeks' remobilisation

\begin{tabular}{|c|c|c|c|c|c|c|}
\hline \multirow[b]{2}{*}{ Sample site } & \multicolumn{3}{|c|}{ After immobilisation (dogs 40 weeks of age) } & \multicolumn{3}{|c|}{ After remobilisation (dogs 90 weeks of age) } \\
\hline & Control & Immobilised & Contralateral & Control & Remobilised & Contralateral \\
\hline \multicolumn{7}{|c|}{ Total incorporation rate $(\mathrm{pmol} / \mathrm{mg}$ wet weight $/ \mathrm{h})$} \\
\hline FPI & $24.0(6.7)(8)$ & $25.7(13.4)(8)$ & $25.2(9.2)(8)$ & $18.9(9.8)(9)$ & $16.6(7.1)(9)$ & $18.7(5.5)(8)$ \\
\hline FMA & $21.4(5.8)(8)$ & $19.6(8.7)(8)$ & $23.6(9.0)(8)$ & $21.1(8.3)(8)$ & $27.2(10.7)(9)$ & $19.6(5.5)(9)$ \\
\hline $\mathrm{TM}$ & $16.4(5.7)(8)$ & $18.3(3.2)(8) \ddagger$ & $21.9(5.4)(8)$ & $9.5(4.7)(8)$ & $7.2(4.3)(9)$ & $11.9(8.5)(9)$ \\
\hline \multicolumn{7}{|c|}{ Chondroitin 6-sulphate/chondroitin 4-sulphate, ultraviolet absorbance } \\
\hline FPI & $1.9(0.3)(7)$ & $1.5(0.3)(8)+5$ & $1.8(0.3)(8)$ & $2.0(0.3)(9)$ & $2.1(0.3)(8)$ & $2.1(0.3)(9)$ \\
\hline FMA & $1.7(0.3)(7)$ & $1.5(0.3)(7) \int$ & $1.9(0.3)(7)$ & $1.8(0.6)(9)$ & $2.1(0.3)(9)$ & $2.1(0.3)(9)$ \\
\hline $\mathrm{TM}$ & $2.1(0.3)(8)$ & $1.9(0.3)(8)^{\star}$ & $2.0(0.3)(8)$ & $2.6(0.3)(8)$ & $2.4(0.3)(9) \ddagger$ & $2.6(0.3)(9)$ \\
\hline \multicolumn{7}{|c|}{ Chondroitin 6-sulphate/chondroitin 4-sulphate, radioactivity } \\
\hline FPI & $2.9(0.5)(8)$ & $2.8(0.8)(7)$ & $2.5(1.0)(7)$ & $2.8(0.6)(9)$ & $3.2(0.5)(8) \dagger$ & $3.2(0.3)(9)$ \\
\hline FMA & $3.1(0.8)(7)$ & $2.8(0.5)(7) \$$ & $3.2(0.5)(7)$ & $2.3(0.5)(8)$ & $2.8(0.3)(9)$ & $2.8(0.2)(9)$ \\
\hline $\mathrm{TM}$ & $3.5(0.8)(8)$ & $3.2(0.8)(8)$ & $3.9(0.8)(7)$ & $3.8(0.7)(6)$ & $3.2(0.5)(8)$ & $3.1(0.2)(8)$ \\
\hline
\end{tabular}

Wilcoxon's matched pairs signed ranks test was used for the statistical analysis; number of animals in each group is shown in parantheses after mean (SD).

${ }^{\star} \mathrm{p} \leq 0.05, \dagger \mathrm{p} \leq 0.02$ immobilised or remobilised versus control.

$\ddagger \mathrm{p} \leq 0.05, \S \mathrm{p} \leq 0.02$ immobilised or remobilised versus contralateral.

For abbreviations of the sample sites, see figure 1.

depending on the sample site. The only statistically significant difference between the age matched control and immobilised groups, however, was observed in the anterior section of the medial condyle of the femur (FMA), where the extractability decreased after immobilisation from $89.7(2.2) \%$ to 86.7 (3.0)\% (mean (SD), $\mathrm{p} \leq 0.05)$. No significant changes in the extractability were observed in the remobilised animals.

\section{PROTEOGLYCAN SYNTHESIS}

The $\left[{ }^{35} \mathrm{~S}\right]$ sulphate incorporation of the samples was determined to estimate the rate of proteoglycan synthesis in three sites of the immobilised, remobilised, and contralateral canine knees. In general, the level of $\left[{ }^{35} \mathrm{~S}\right]$ sulphate incorporation rate was similar to that found earlier in canine knee and hip joints. ${ }^{2633}$ The incorporation rate in the immobilised and its contralateral limb was not significantly different from that in the joints of the control animals (table 1). However, in the medial condyle of tibia (TM), the incorporation rate was significantly higher in the contralateral joint as compared with the immobilised knee. After 50 weeks of remobilisation, the total synthesis rates did not differ between the three analysis groups at any sample site.

\section{DETERMINATION OF CHONDROITIN SULPHATE} ISOMERS

The proportions of monosulphated chondroitin sulphate isomers were determined by high performance liquid chromatography from samples digested by chondroitinase AC to release the unsaturated chondroitin sulphate disaccharides. In all of the groups, the amount of unsaturated 6-sulphated disaccharide was higher in comparison with 4-sulphated (table 1 ). In the newly synthesised proteoglycans, the relative proportion of chondroitin 6-sulphate was remarkably higher than in the total pool of tissue proteoglycans.

In all three sample sites analysed, there was a reduction of both monosulphated chondroitin sulphate isomers after immobilisation. The relative decline, however, was always larger in chondroitin 6-sulphate. Therefore, the ratio of chondroitin 6-sulphate to chondroitin 4-sulphate decreased in the immobilised joints, and a similar trend was seen in the newly synthesised chondroitin sulphate isomers (table $1)$.

After 50 weeks of remobilisation, the ratio of chondroitin 6-sulphate to chondroitin 4-sulphate was more than restored in the remobilised femur, in radiolabelled proteoglycans a significant increase over controls was found in FPI. No such rebound effect was present in tibia (TM), where the value of the immobilised joint remained significantly lower than that of the contralateral one (table 1).

\section{GEL FILTRATION OF PROTEOGLYCANS}

Immobilisation slightly increased the average size of resident proteoglycans in the medial femoral condyle (FMA) both in the immobilised and its contralateral joint (fig 2A). A similar size increase was found in the newly synthesised proteoglycans of this site (fig 2B). After 50 weeks' remobilisation period, the newly synthesised proteoglycans in FMA continued to be larger than those in the age matched controls (fig 2D). Other sites often showed a similar but less obvious increase in proteoglycan monomer size before and after 50 weeks' remobilisation (data not shown). No pronounced changes in the average size of glycosaminoglycan chains could be observed by Sephacryl S-300 gel filtration (data not shown).

\section{B3 EPITOPE}

The appearance of the epitopes recognised by the monoclonal antibody $3 \mathrm{~B} 3$ in proteoglycans undigested with chondroitinase ABC was investigated in agarose gel blots. No changes in the signal of these $3 \mathrm{~B} 3(-)$ epitopes was found after immobilisation, neither in the immobilised nor its contralateral joint. Intense staining of 3B3 epitopes was evident after chondroitinase ABC treatment (results not shown), similar to a previous report. ${ }^{34}$

\section{Discussion}

Several earlier studies have indicated that immobilisation causes a reduction in cartilage proteoglycans, ${ }^{5713-15171835}$ but the long term reversibility has not been investigated in detail. The most important finding of this study was 

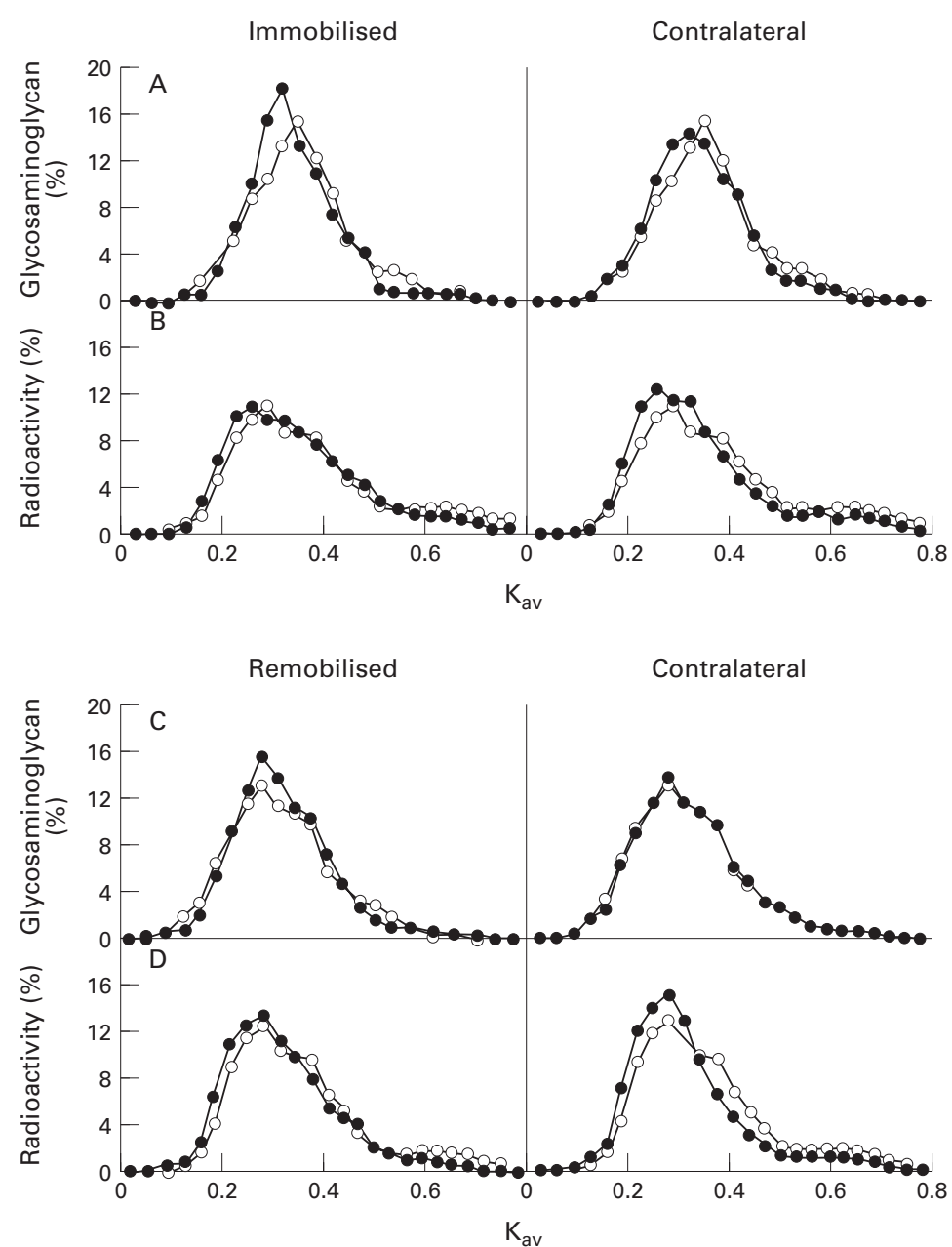

Figure 2 Immobilisation and remobilisation effects on proteoglycan size analysed with Sephacryl S-500 gel filtration. Pooled extracts from the immobilised anterior medial femoral condyle (FMA) and its contralateral joint ( $A$ and $B$, respectively), and remobilised and its contralateral joint ( $C$ and $D$, respectively) were chromatographed in the presence of $4 M$ $G u C l$, and the fractions were analysed for total proteoglycans ( $A$ and $C$ ) and for radioactivity $(B$ and $D)$. Each chromatography was repeated three times to confirm the changes in the profiles. Open symbols represent samples from the control group, and closed symbols those from the immobilised/remobilised limbs, treated and contralateral shown in separate panels. that remained comparatively low even after 50 weeks' normal physical activity, and one of these (FPS) was actually significantly lower than in the age matched controls. Thus, it is concluded that in certain joint surface areas the reduction of proteoglycans associated with a period of cast immobilisation before skeletal maturity, is persistent, if not permanent.

The significant changes in the concentration of proteoglycans in the articular cartilage of the contralateral limb that occurred between 15 and 50 weeks after the immobilisation were rather unexpected. A plausible explanation for this finding is that the period of immobilisation changed the gait or loading profile of the contralateral limb, and that the consequences of the altered activity patterns were realised relatively slowly in the composition of the matrix. This view further suggests that cartilage matrix structure remains subject to modulation by joint dynamics even after skeletal maturation (complete before the end of the 15 weeks of remobilisation), as noted before in skeletally mature mongrel dogs. ${ }^{56}$ The unexpected reduction of water content, without a change in the uronic acid, in the anterior section of medial femoral condyle (FMA) after remobilisation remains unexplained. However, water content was decreased (dry weight increased) after remobilisation also in an earlier study on canine knee. ${ }^{24}$ In general, the mechanisms controlling the content of water in articular cartilage are currently unknown, although relaxation of the collagen network has been suggested. ${ }^{37}$

The modest changes in the rates of $\left[{ }^{35} \mathrm{~S}\right]$ sulphate incorporation we found in young dogs after immobilisation are comparable with another study on dogs, which showed a non-significant reduction of proteoglycan synthesis in the immobilised side and a slight increase in the contralateral leg. ${ }^{24}$ In adult mongrel dogs, comparison between immobilised and its contralateral joint showed a $41 \%$ reduction in proteoglycan synthesis. ${ }^{5}$ In that study, however, the comparison was made between the immobilised and its contralateral joint, which probably increases the difference. A similar, but less noticeable effect was seen in the tibial condyle of the young dogs in this study. The unchanged proteoglycan synthesis rate in the immobilised leg suggests that increased degradation was involved in the depletion of cartilage proteoglycans. It is also quite possible that a minor change in the synthesis rate is sufficient for a cumulative effect in concentration. A rigid external fixation, permitting minimal or no joint movement at all, showed significantly diminished $\left[{ }^{35} \mathrm{~S}\right]$ sulphate incorporation rates. ${ }^{24}$ The minor changes we found in proteoglycan synthesis are in line with the unaltered expression of the 3B3(-) epitope, ${ }^{34}$ often linked with ongoing anabolic events in early degenerative joint disease.

The loss of proteoglycans after immobilisation has been localised mainly to the superficial and intermediate zones of cartilage. ${ }^{14}$ This fact is in line with our finding that the ratio of chondroitin 6-sulphate to chondroitin (patella, PAT; superior femoropatel ral condyle, FMI) showed proteoglycan values

\begin{abstract}
chondroitin to chondroitin
\end{abstract}


4-sulphate in total tissue proteoglycans was reduced, as chondroitin 6-sulphate is more abundant in the superficial cartilage. ${ }^{38} \mathrm{~A}$ novel finding in this study was that the lowered 6- to 4 -sulphate ratio of chondroitin sulphates is associated with a corresponding change in the newly synthesised proteoglycans, suggesting that the difference in the tissue levels of the isomers was caused by a change in the relative activities of the corresponding transferases, or distribution of proteoglycan types (such as aggrecan and decorin) that exhibit different $6 / 4$-sulphate ratios. The relative amount of chondroitin 6-sulphate was generally higher in the newly synthesised than in the total proteoglycans, as reported earlier in bovine sesamoid bone cultures. ${ }^{39}$ This may be regarded as a sign of higher proteoglycan synthesis (and turnover) in the superficial zone, rich in chondroitin 6-sulphate.

A small but significant increase in the size of the proteoglycans was observed after immobilisation, as noted previously. ${ }^{15}$ A short remobilisation (15 weeks) further increased average aggrecan size, both in the treated and contralateral side..$^{15}$ This size difference to the littermate controls was attenuated but still present after 50 weeks of remobilisation in the anterior section of the medial femoral condyle (FMA). In the other sample sites, however, the average proteoglycan size increase after 15 weeks' remobilisation ${ }^{15}$ had almost disappeared after the current 50 weeks' remobilisation time.

In summary, this study showed that the composition of articular cartilage is prone to longlasting changes caused by cast immobilisation. The proteoglycan depletion was not reversed in all of the cartilage surface sites even after a 50 week remobilisation period. Furthermore, significant changes in the contralateral joint evolved during the later phases of the long remobilisation period, suggesting that the proteoglycan matrix of articular cartilage of the investigated joints remains in a dynamic state even after skeletal maturation. This may be caused by a change in mobility pattern adopted by the animal. However, the role of humoral factors, systemic or possibly derived from the atrophic cartilage, cannot be ruled out.

The authors acknowledge Mrs Elma Sorsa and Mrs Eija Kettunen for their excellent technical assistance, and Ms Eija Antikainen for preparing the photographs.

This study was supported by research grants from the Finnish Research Council for Physical Education and Sports, the Ministry of Education; the Medical Research Council of the Academy of Finland; Jenny and Antti Wihuri Foundation; the Science and Research Foundation of Farmos, the Saastamoinen Science and Research Foundation of Farmos, the Saastamoinen
Foundation, the North-Savo Fund of the Finnish Cultural Foundation, the North-Savo Fund of the Finnish Cultural
Foundation, the Finnish Rheumatological Foundation, and the Foundation, the Finnish Rheumatological Foundation, and the
Siviä Kosti Foundation. Dr Matti O Jortikka is a recipient of a Siviä Kosti Foundation. Dr Matti O Jortikka is a recipient of a
research grant from the TULES Graduate School and the research grant from
Academy of Finland.

1 Hascall V C. Proteoglycans: the chondroitin sulfate/keratan sulfate proteoglycans of cartilage. ISI Atlas of Science. Biochemistry 1988;1:189-98.

2 Mow V C, Ratcliffe A, Poole A R. Cartilage and diarthrodia joints as paradigms for hierarchical materials and structures. Biomaterials 1992;13:67-97.

3 Tammi M, Paukkonen K, Kiviranta I, Jurvelin J, Säämänen A-M, Helminen H J. Joint loading-induced alterations in articular cartilage. In: Helminen H J, Kiviranta I, Tamm M, Säämänen A-M, Paukkonen K, Jurvelin J, eds. foint $\mathrm{M}$, Säämänen A-M, Paukkonen $\mathrm{K}$, Jurvelin J, eds. Foint loading-biology and
Wright, 1987:64-88.
4 Langenskiöld A, Michelsson J-E, Videman T. Osteoarthritis of the knee in the rabbit produced by immobilization. Acta of the knee in the rabbit prod
Orthop Scand 1979;50:1-14.

5 Palmoski M, Perricone E, Brandt K D. Development and reversal of a proteoglycan aggregation defect in normal canine knee cartilage after immobilization. Arthritis Rheum 1979;22:508-17.

6 Helminen H J, Kiviranta I, Säämänen A-M, Jurvelin J S, Arokoski J, Oettmeier R, et al. Effect of motion and load on articular cartilage in animal models. In: Kuettner K, Schleyerbach R, Peyron J G, Hascall V C, eds. Articular cartilage and osteoarthritis. New York: Raven Press, 1992:501-10.

7 Palmoski M J, Colyer R A, Brandt K D. Joint motion in the absence of normal loading does not maintain normal articular cartilage. Arthritis Rheum 1980;23:325-34.

8 Grumbles R M, Howell D S, Howard G A, Roos B A, Setton L A, Mow V C, et al. Cartilage metalloproteases in diston L A, Mow V C, et al. Cartilage metalloproteas

9 Paukkonen K, Jurvelin J, Helminen H J. Effects of immobilization on the articular cartilage in young rabbits. A quantitative light microscopic stereologic study. Clin Orthop 1986;206:270-80

10 Palmoski M J, Brandt K D. Immobilization of the knee prevents osteoarthritis after anterior cruciate ligament transection. Arthritis Rheum 1982;25:1201-8.

11 Williams $J$ M, Brandt $\mathrm{K}$ D. Immobilization ameliorates chemically-induced articular cartilage damage. Arthritis Rheum 1984;27:208-16.

12 Kostenszky K S, Olah E H. Effect of increased functional demand on the glycosaminoglycan (mucopolysaccharide) content of the articular cartilage. Acta Biol Hung 1972; 23:75-82.

13 Caterson B, Lowther D A. Changes in the metabolism of the proteoglycans from sheep articular cartilage in response to mechanical stress. Biochim Biophys Acta 1978;540:41222 .

14 Kiviranta I, Jurvelin J, Tammi M, Säämänen A-M, Helminen $\mathrm{H} \mathrm{J}$. Weight bearing controls glycosaminoglycan concentration and thickness of articular cartilage in the knee joints of young beagle dogs. Arthritis Rheum 1987;30:801-8.

15 Säämänen A-M, Tammi M, Jurvelin J, Kiviranta I, Helminen H J. Proteoglycan alterations following immobilization and remobilization in the articular cartilage of young canine knee (stifle) joint. J Orthop Res 1990;8:863-73.

16 Videman T, Eronen I, Friman C. Glycosaminoglycan metabolism in experimental osteoarthritis caused by immobilization. The effects of different periods of immobilization and follow-up. Acta Orthop Scand 1981; 52:11-21.

17 Tammi M, Säämänen A-M, Jauhiainen A, Malminen O, Kiviranta I, Helminen H. Proteoglycan alterations in rabbit knee articular cartilage following physical exercise an immobilization. Connect Tissue Res 1983;11:45-55.

18 Golding J, Ghosh P. Drugs for osteoarthrosis II: The effects of a glycosaminoglycan polysulphate ester (Arteparon) on proteoglycan aggregation and loss from articular cartilage of immobilized rabbit knee joints. Curr Ther Res 1983;34:67-80.

19 Oláh E H, Kostenszky K S. Effect of altered functional demand on the glycosaminoglycan content of the articular cartilage of dogs. Acta Biol Acad Sci Hung 1972;23:195200

20 Evans E B, Eggers G W N, Butler J K, Blumel J. Experimental immobilization and remobilization of rat knee joints. J Bone Joint Surg Am 1960;42:737-58.

21 Sood S C. A study of the effects of experimental immobilisation on rabbit articular cartilage. J Anat 1971;108:497507.

22 Finsterbush A, Friedman B. Early changes in immobilized rabbit knee joints: A light and electron microscopic study. Clin Orthop 1973;92:305-10.

23 Jurvelin J, Kiviranta I, Säämänen A-M, Tammi M, Helminen H J. Partial restoration of immobilizationinduced softening of canine articular cartilage after remobilization of the knee (stifle) joint. J Orthop Res 1989;7:352-8.

24 Behrens F, Kraft E L, Oegema T R. Biochemical changes in articular cartilage after joint immobilization by casting or external fixation. J Orthop Res 1989;7:335-43.

25 Committee on Care and use of Laboratory Animals of the Institute of Laboratory Animal Resources Commission on Life Sciences, National Research Council. Guide for the care and use of laboratory animals. Bethesda: Public Health care and use of laboratory animals. Bethesda:

26 Lammi M J, Häkkinen T P, Parkkinen J J, Hyttinen M M, Jortikka M, Helminen $\mathrm{H}$ J, et al. Adaptation of canine femoral head articular cartilage to long-distance running exercise in young beagles. Ann Rheum Dis 1993;52:36977.

27 Kääpä E, Holm S, Inkinen R, Lammi M J, Tammi M, Vanharanta $\mathrm{H}$. Proteoglycan chemistry after experimental intervertebral disc injury. J Spinal Disord 1994;7:296-306.

28 Blumenkrantz N, Asboe-Hansen G. New method for quantitative determination of uronic acids. Anal Biochem 1973;54:484-9

29 Säämänen A-M, Tammi M, Kiviranta I, Jurvelin J, Helminen H J. Levels of chondroitin-6-sulfate and nonaggregating proteoglycans at articular cartilage contact sites in the knees of young dogs subjected to moderate running exercise. Arthritis Rheum 1989;32:1282-92.

30 Christner J E, Caterson B, Baker J R. Immunological determinants of proteoglycans. Antibodies against the unsatu- 
rated oligosaccharide products of chondroitinase $\mathrm{ABC}$ digested cartilage proteoglycans. J Biol Chem 1980; 255:7102-5.

31 Lammi M, Tammi M. Densitometric assay of nanogram quantities of proteoglycans precipitated on nitrocellulose membrane with Safranin O. Anal Biochem 1988; 168:352-7

32 Jortikka M, Lammi M J, Parkkinen J J, Lahtinen R, Tammi M I. A high sensitivity dot-blot assay for proteoglycans by cuprolinic blue precipitation. Connect Tissue Res 1993; 29:263-72

33 Sandy J D, Adams M E, Billingham M E J, Plaas A, Muir H. In vivo and in vitro stimulation of chondrocyte biosynthetic activity in early experimental osteoarthritis. Arthritis Rheum 1984;27:388-97.

34 Ratcliffe A, Shurety W, Caterson B. The quantitation of a native chondroitin sulfate epitope in synovial fluid lavages and articular cartilage from canine experimental osteoarand articular cartilage from canine experimental osteoar-
thritis and disuse atrophy. Arthritis Rheum 1993;36:54351 .

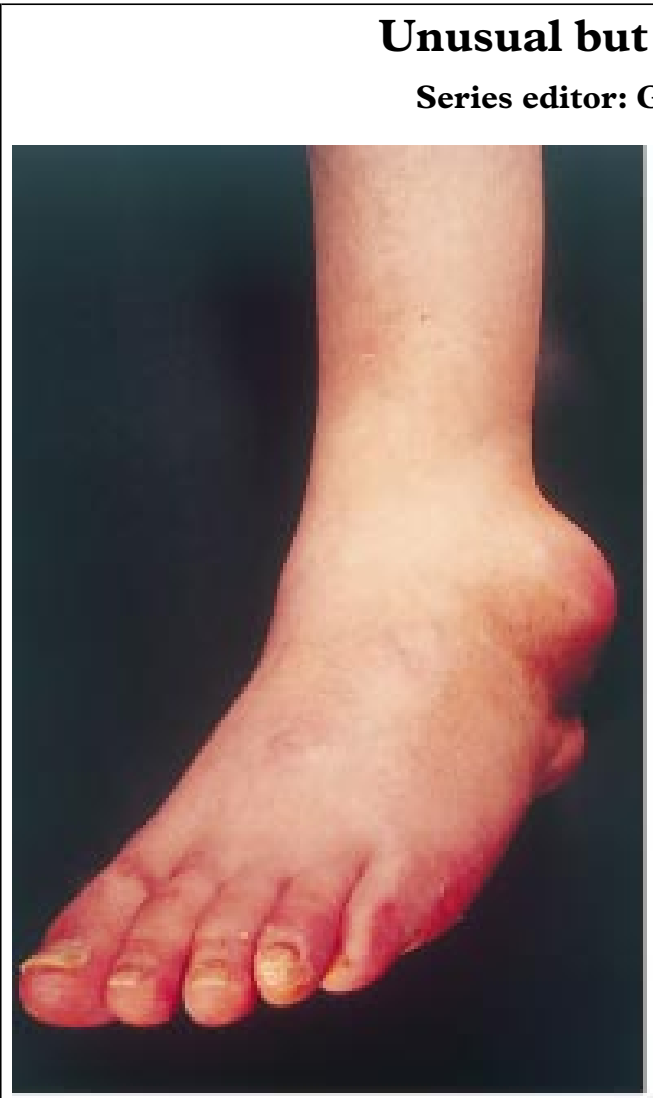

This 48 year old man developed alcohol induced pancreatitis. During the admission he developed a florid, patchy panniculitis with fluctuent swellings over his elbows, wrists, knees and ankles (figure, top left) and an asymmetric polyarthritis affecting large and small joints. Sterile pus was aspirated from the subcutaneous swellings and several joints; staining of synovial fluid was positive for lipid. Radiographs showed a severe destructive chondropathy, patchy osteoporosis, erosions, osteolytic lesions, and periostitis (figure, right panels).

The bone lesions in pancreatic arthropathy are thought to result from medullary fat necrosis ${ }^{1}$ secondary to high circulating lipase concentrations. The inflammatory arthropathy may result from excess concentrations of intra-articular free fatty acids derived from lipoproteins or hydrolysis of local adipose tissue. ${ }^{2}$ Chronic pancreatitis or carcinoma of the pancreas may also cause this rare arthropathy. There is no specific treatment and the locomotor outcome is poor.

1 Gibson TJ, Schumacher HR, Pascual E, Brighton C. Arthropathy, skin and bone lesions in pancreatic disease. J Rheumatol 1975;2:7-13.

2 Simkin PA, Brunzell JD, Wisner D, Fiechtner JJ, Carlin JS, Willkens RF. Free fatty acids in the pancreatitic arthritis syndrome. Arthritis Rheum 1983;26:127-32.

Contributors: GARY D WRIGHT, DES GREEN, MICHAEL DOHERTY. City Hospital, Nottingham, NG5 1PB, United Kingdom.
35 Eronen I, Videman T, Friman C, Michelsson J-E. Glycosaminoglycan metabolism in experimental osteoarthrosis caused by immobilization. Acta Orthop Scand 1978;49:329-34.

36 Palmoski M J, Brandt K D. Running inhibits the reversal of atrophic changes in canine knee cartilage after removal of a leg cast. Arthritis Rheum 1981;24:1329-37.

37 Bonassar L J, Frank E H, Murray J C, Paguio C G, Moore V $\mathrm{L}$, Lark M W, et al. Changes in the composition and physical properties due to stromelysin degradation. Arthritis Rheum 1995;38:173-83.

38 Mourão P A S. Distribution of chondroitin 4-sulfate and chondroitin 6-sulfate in articular and growth cartilage. Arthritis Rheum 1988;31:1028-33.

39 Korver G H V, van de Stadt R J, van Kampen G P, Kiljan E, van der Korst J K. Bovine sesamoid bones: a culture system for anatomically intact articular cartilage. In Vitro Cell Dev Biol 1989;25:1099-106. 